Pesq. Vet. Bras. 38(6):1159-1171, junho 2018

\title{
Complicações observadas em cães e gatos com doenças neurológicas $^{1}$
}

\author{
Marina B. Santoro² e Mônica V. Bahr Arias ${ }^{2 *}$
}

\begin{abstract}
Santoro M.B. \& Bahr Arias M.V. 2018. [Complications observed in dogs and cats with neurological diseases]. Complicações observadas em cães e gatos com doenças neurológicas. Pesquisa Veterinária Brasileira 38(6):1159-1171. Departamento de Clínicas Veterinárias, Universidade Estadual de Londrina, Rodovia Celso Garcia Cid PR-445 Km 380, Campus Universitário, Londrina, PR 86051-990, Brazil. E-mail: vicky@uel.br

Dogs and cats with neurological diseases can show several sequelae and complications as a result of motor, sensory and visceral deficiencies. Some complications are an important cause of mortality, mainly complications related to spinal cord injury. The aim of this study was to evaluate in 100 dogs and cats brought to the Neurology Service of Veterinary Hospital from Universidade Estadual de Londrina the frequency of complications, epidemiology, lesion localization and etiology, still assessing the evolution and survival time. It was observed that $91 \%$ of the animals developed complications. The most frequent were muscular atrophy $(n=32)$, urinary retention $(n=24)$, urinary incontinence $(n=24)$, fecal incontinence $(n=17)$ and pressure sores $(\mathrm{n}=16)$. The main site of injury associated with the onset of complications was spinal cord (91\%) and the main cause was the spinal cord trauma (37.3\%). The median survival time of animals with complications was two months and the mean was seven months. The main causes of death or euthanasia were related do spinal cord trauma, traumatic brain injury or inflammatory/infectious disease. The estimated lifetime was lower for older and heavier animals. Although the survival rate of animals with complications was high, most of them remained with sequelae, indicating that survival does not mean normal functional capacity. Dogs and cats with neurological problems require a high degree of attention of the veterinarian and their guardians, and guidelines regarding the real expectation of recovery and management difficulties that may be encountered in the course of the disease are essential.
\end{abstract}

INDEX TERMS: Neurological diseases, nervous system, complications, rehabilitation, dogs, cats.

RESUMO.- Cães e gatos com problemas neurológicos estão sujeitos a várias sequelas e complicações, em decorrência das deficiências motoras, sensoriais e viscerais. Algumas complicações estão relacionadas a maior mortalidade, principalmente aquelas relacionadas ao trauma vertebromedular. O objetivo do presente estudo foi avaliar nessas espécies a frequência do aparecimento de complicações, a epidemiologia, localização da lesão e etiologia, avaliando ainda a evolução e o tempo de sobrevida. Foram acompanhados 100 cães e gatos com doenças neurológicas trazidos para atendimento no Serviço de Neurologia do Hospital Veterinário da Universidade Estadual de Londrina. Observou-se que 91\% dos animais

\footnotetext{
${ }^{1}$ Recebido em 23 de janeiro de 2017.

Aceito para publicação em 21 de junho de 2017.

${ }^{2}$ Departamento de Clínicas Veterinárias, Universidade Estadual de Londrina (UEL), Campus Universitário, Rodovia Celso Garcia Cid PR-445 Km 380, Londrina, PR 86051-990, Brasil. *Autor para correspondência: vicky@uel.br
}

desenvolveram complicações, sendo que as mais frequentes foram atrofia muscular $(\mathrm{n}=32)$, retenção urinária $(\mathrm{n}=24)$, incontinência urinária $(n=24)$, incontinência fecal $(n=17)$ e feridas de decúbito $(\mathrm{n}=16)$. 0 principal local de lesão associado ao aparecimento das complicações foi medula espinhal $(91,3 \%)$ e a principal etiologia foi o trauma vertebromedular (37,3\%). 0 tempo mediano e médio de vida estimado foram, respectivamente, dois e sete meses sendo que as principais causas de morte ou eutanásia estavam relacionadas ao trauma vertebromedular, trauma cranioencefálico ou doença inflamatória/infecciosa. 0 tempo de vida estimado foi menor para animais mais velhos e mais pesados. Embora o índice de sobrevivência dos animais com complicações tenha sido alto, muitos permaneceram com sequelas, indicando que a sobrevivência não significou capacidade funcional normal. Cães e gatos com problemas neurológicos requerem alto grau de atenção do veterinário e de seus tutores, sendo 
fundamental a orientação a respeito da real expectativa de recuperação e das dificuldades de manejo que poderão ser encontradas no curso da doença.

TERMOS DE INDEXAÇÃO: Neurologia, sistema nervoso, complicações, reabilitação, cães, gatos.

\section{INTRODUÇÃO}

A incidência de doenças neurológicas em cães e gatos é muito alta na rotina de pequenos animais (Sharp \& Wheeler 2005a, De Lahunta \& Glass 2015a). Como a maioria das afecções causam disfunções motoras, sensoriais e viscerais, podem ocorrer várias complicações, sendo as mais frequentes as úlceras de decúbito, feridas pela perda da sensibilidade, retenção ou incontinência urinária, infecção do trato urinário, assaduras, contraturas musculares, anquiloses, atrofia muscular, complicações gastrointestinais e respiratórias (Sharp \& Wheeler 2005b).

A manutenção do animal pode ser inviabilizada pelas complicações existentes ou previstas, sendo a comunicação com o proprietário fundamental para reduzir os riscos de desentendimentos e melhorar a qualidade de vida do paciente (Bonvicini \& Cornell 2007). Cabe ao veterinário reconhecer o potencial de aparecimento das complicações, conscientizar o tutor quanto ao quadro clínico e, principalmente, orientá-lo em relação à importância da prevenção das complicações e intervenções para evitá-las ou tratá-las.

Grande parte do sucesso no tratamento das afecções neurológicas é resultado do manejo adequado (Jerram et al. 1997), que requer dedicação especial e cuidados intensivos consideráveis, dependendo principalmente do esforço e da disponibilidade do tutor em garantir os cuidados de enfermagem necessários, como manter o animal em um local seco e acolchoado, realizar o correto manejo da micção, defecação, troca de decúbito frequente e fisioterapia (Nicoll \& Remedios 1995, Jerram et al. 1997).

Alguns estudos avaliaram a qualidade de vida dos animais com lesões medulares (Levine et al. 2008) ou o tempo gasto pelos tutores para cuidar desses pacientes (Freeman et al. 2013), entretanto, existem poucos trabalhos avaliando a ocorrência das complicações em cães e gatos com problemas neurológicos. 0 objetivo do presente estudo foi avaliar nessas espécies a frequência do aparecimento de complicações, a epidemiologia, localização da lesão e etiologia, avaliando ainda a evolução do quadro e o tempo de sobrevida.

\section{MATERIAL E MÉTODOS}

Foram avaliados cães e gatos com problemas neurológicos trazidos para atendimento no Programa Prática Hospitalar em Neurologia Veterinária da Universidade Estadual de Londrina (UEL), de agosto de 2013 a fevereiro de 2016.

Os cães e gatos foram submetidos ao exame clínico e neurológico para a localização da lesão e, dependendo da suspeita, indicação clínica e disponibilidade do tutor; foram realizados os seguintes exames complementares para diagnóstico ou exclusão de diversas afecções: hemograma e bioquímica sérica, gasometria, urinálise, PCR para cinomose e erlichiose, sorologia para toxoplasmose e neosporose, radiografia simples, ultrassonografia (US), análise do líquido cerebroespinhal (LCE), mielografia e tomografia computadorizada (TC).
Após o diagnóstico, os cães e gatos foram submetidos ao tratamento clínico e/ou cirúrgico. Os tutores foram orientados a realizar a prevenção e o tratamento apropriado das complicações. 0 acompanhamento foi feito por meio dos retornos agendados e telefonemas para os tutores, observando-se a evolução do quadro, ocorrência de complicações, resolução do quadro, morte ou opção pela eutanásia.

Os casos foram tabulados de acordo com a localização da lesão (medula espinhal, encéfalo, sistema nervoso periférico ou síndrome multifocal). Em todos os casos foram coletados os seguintes dados: resenha, principal queixa, exame físico e neurológico, presença de doenças concomitantes, exames complementares, diagnóstico, tratamento, ocorrência de complicações, evolução dos sinais neurológicos, resolução do quadro ou eutanásia/morte.

A localização das lesões medulares foi classificada de acordo com o segmento medular afetado (cervical, cervicotorácico, toracolombar ou lombossacro) e o grau de lesão medular, sendo que a região lombossacra ainda foi dividida em lombossacra cranial e lombossacra caudal, devido à particularidade dos sinais clínicos observados nas doenças da cauda equina (Sharp \& Wheeler 2005b, De Lahunta \& Glass 2015a). Foram considerados os seguintes graus de lesão medular: nos segmentos medulares cervical (C1-C5) e cervicotorácico (C6-T2) - grau I (dor), grau II (dor e ataxia), grau III (dor, tetraparesia, tetraplegia); segmento toracolombar (T3-L3) e lombossacro cranial (L4-L6) - grau I (dor), grau II (ataxia e diminuição da propriocepção), grau III (paraplegia), grau IV (paraplegia e retenção ou incontinência urinária) e grau V (idem 4 associado a perda da sensibilidade dolorosa profunda); segmento lombossacro caudal (L7-S3) grau I (dor), grau II (dor e paresia), grau III (dor, incontinência urinária, cauda flácida, esfíncteres relaxados) e grau IV (dor, cauda flácida, retenção urinária). As lesões encefálicas foram localizadas em talamocórtex, cerebelo ou tronco encefálico e as doenças do Sistema Nervoso Periférico foram classificadas em nervos periféricos, junção neuromuscular ou músculo. Quando os sinais neurológicos envolviam mais de um local, sendo os mesmos contíguos (exemplo: tronco encefálico e medula espinhal cervical, ou região toracolombar e lombossacra), a síndrome foi classificada como difusa. Já quando os sinais neurológicos envolviam mais de um local, mas distantes (exemplo: talamocortex e medula espinhal, ou tronco encefálico e medula espinhal toracolombar), a síndrome foi classificada como multifocal (Dewey \& Da Costa 2016).

Considerou-se disfunção motora a presença de paresia ou plegia de um ou mais membros, ou diminuição ou ausência da função motora dos nervos cranianos motores (Braund 1994). As disfunções sensoriais analisadas foram analgesia cutânea, automutilação, presença de ulcerações e ausência de resposta ao teste de sensibilidade superficial ou profunda nos membros (Braund 1994). As alterações cognitivas consideradas foram alteração do conteúdo da consciência, como demência, falha em reconhecer o proprietário ou ambientes familiares e andar compulsivo (De Lahunta \& Glass 2015a). As alterações viscerais analisadas foram a presença de retenção urinária do tipo neurônio motor superior, ou seja, vesícula urinária repleta com resistência ao esvaziamento manual, e incontinência urinária do tipo neurônio motor inferior, ou seja, presença de vesícula urinária repleta, com gotejamento de urina e pouca resistência ao esvaziamento manual. Outras alterações viscerais estudadas foram a presença de infecção urinária em decorrência de retenção urinária, incontinência fecal (evacuação 
em momentos inapropriados), relaxamento do esfíncter anal e megaesôfago (Braund 1994). Foram consideradas alterações mistas a presença de alterações associadas, como presença de paraplegia (disfunção motora) e retenção urinária (alteração visceral), por exemplo. A perda de massa muscular ou atrofia foi avaliada por palpação e observação de cada grupo muscular conforme descrito por Lorenz et al. (2011b). A seguir são apresentados os critérios utilizados para o diagnóstico das principais afecções estudadas (Sharp \& Wheeler 2005b, De Lahunta \& Glass 2015a, Dewey \& Da Costa 2016):

Doença do disco intervertebral: dor cervical ou toracolombar, ou histórico de disfunção motora aguda em membros, associado à dor focalizada em coluna, presença de exames laboratoriais normais, líquido cerebroespinhal normal ou com leve aumento de proteínas e células, mielografia com desvio da coluna de contraste em local compatível com a síndrome medular, retirada de material do disco durante a cirurgia (Brisson 2010).

Trauma vertebromedular: presença de dor ou disfunção motora após trauma, presença de lesões em outros sistemas associadas à trauma, exame de imagem com alterações compatíveis com fratura ou luxação vertebral, ou presença de compressão medular na mielografia (Jeffery 2010, Araújo et al. 2015).

Meningomielite, meningoencefalite, meningoencefalomielite e meningite inflamatória não infecciosa: histórico de alteração neurológica aguda, sem sinais sistêmicos, exames laboratoriais normais, líquido cerebroespinhal com pleocitose leve, moderada ou intensa, aumento de proteínas, sorologia para toxoplasmose e neospora normal, PCR de ehrlichia e cinomose negativo e melhora do quadro após uso de corticoide ou outros fármacos imunossupressores, como ciclosporina ou azatioprina.

Meningomielite, meningoencefalite, meningoencefalomielite e meningite inflamatória infecciosa: histórico de sinais sistêmicos prévios, ou presença de sinais sistêmicos tais como secreção ocular, conjuntivite, ou uveíte associado a sinais neurológicos durante o exame clínico, exames laboratoriais com alterações, como anemia, leucopenialeucicitose/linfopenia/eosinofilia/trombocitopenia, alterações nos exames bioquímicos, líquido cerebroespinhal com alterações como pleocitose e/ou aumento de proteínas, sorologia positiva (toxoplasmose $>1: 1024$; neosporose $>1: 50$ ) ou PCR do sangue positivo em caso de erliquiose ou PCR de urina positivo em caso de cinomose.

Trauma craniano: presença de alterações neurológicas encefálicas associadas à ocorrência de trauma recente, presença de lesões associadas ao trauma, como pneumotórax, feridas, hematoma, alterações compatíveis com fraturas de ossos cranianos em radiografias simples, escala de coma alterada e outras causas de alteração de consciência, como anemia, hipoglicemia, e alterações hidroeletrolíticas descartadas por meio de exames laboratoriais.

Síndrome da cauda equina: presença de paresia ou fraqueza de membros posteriores e/ou dor à palpação da articulação lombossacra e/ou paresia/plegia da cauda ou automutilação da mesma, associado à alterações na radiografia simples ou da mielografia ou TC compatíveis com estenose lombosacra.

Mielopatia degenerativa: presença de mielopatia crônica, lentamente progressiva (meses), sem hiperpatia, sem alterações na radiografia simples, sem alterações na mielografia e na análise do LCE.
Infarto fibrocartilaginoso: presença de mielopatia aguda, sem hiperpatia, sem alterações na radiografia simples, sem alterações na análise do LCE e sem alterações compressivas ou expansivas na mielografia.

Para a avaliação da evolução do quadro, considerou-se a ocorrência de recuperação total, presença de disfunções (motoras, sensoriais, viscerais, cognitivas ou mistas), ocorrência de morte ou opção pela eutanásia.

Análise estatística. A avaliação da estimativa do tempo de sobrevivência dos animais foi realizada por meio do estimador de Kaplan-Meier (Colosimo \& Giolo 2006). Curvas de sobrevivência foram obtidas para as covariáveis sexo, idade e peso. 0 teste logrank foi utilizado para verificar a presença de diferenças significativas entre as curvas obtidas para as categorias de cada covariável. 0 evento de interesse, denominado como tempo de falha, foi definido como o tempo até a morte ou eutanásia dos animais.

\section{RESULTADOS}

Dos 100 cães e gatos avaliados, 91\% (75 cães e 16 gatos) desenvolveram complicações (Quadro 1), sendo que as mais frequentes foram atrofia muscular $(n=32)$, retenção urinária

Quadro 1. Sexo, raça, idade e peso 83 cães e 17 gatos com doenças neurológicas atendidos no HV/UEL de 2013 a 2016

\begin{tabular}{|c|c|c|c|c|c|c|}
\hline & & \multicolumn{2}{|c|}{ Cães } & \multicolumn{2}{|c|}{ Gatos } & \multirow{3}{*}{ TOTAL } \\
\hline & & \multicolumn{4}{|c|}{ Complicações } & \\
\hline & & Sim & Não & Sim & Não & \\
\hline \multirow[t]{2}{*}{ Sexo } & Fêmea & 39 & 5 & 7 & 1 & 52 \\
\hline & Macho & 36 & 3 & 9 & 0 & 48 \\
\hline \multirow[t]{17}{*}{ Raça } & SRD & 40 & 6 & 16 & 1 & 63 \\
\hline & Lhasa Apso & 6 & 0 & - & - & 6 \\
\hline & Poodle & 5 & 1 & - & - & 6 \\
\hline & Daschund & 4 & 0 & - & - & 4 \\
\hline & Labrador & 3 & 0 & - & - & 3 \\
\hline & Shih Tzu & 3 & 0 & - & - & 3 \\
\hline & Pastor Alemão & 2 & 0 & - & - & 2 \\
\hline & Pinscher & 2 & 0 & - & - & 2 \\
\hline & Pit bull & 2 & 0 & - & - & 2 \\
\hline & Schnauzer & 2 & 0 & - & - & 2 \\
\hline & Boxer & 1 & 0 & - & - & 1 \\
\hline & Blue heeler & 1 & 0 & - & - & 1 \\
\hline & Cocker Spaniel & 1 & 0 & - & - & 1 \\
\hline & Dogo Argentino & 1 & 0 & - & - & 1 \\
\hline & Spitz Alemão & 1 & 0 & - & - & 1 \\
\hline & Weimaraner & 1 & 0 & - & - & 1 \\
\hline & Rottweiller & 0 & 1 & 0 & 0 & 1 \\
\hline \multirow[t]{4}{*}{ Idade } & 0 a 1 ano & 19 & 2 & 12 & 0 & 33 \\
\hline & 1 a 5 anos & 27 & 2 & 3 & 0 & 32 \\
\hline & 6 a 10 anos & 15 & 1 & 1 & 1 & 18 \\
\hline & $>10$ anos & 14 & 3 & 0 & 0 & 17 \\
\hline \multirow[t]{3}{*}{ Peso } & $<5 \mathrm{~kg}$ & 21 & 1 & 14 & 0 & 36 \\
\hline & 5 a $20 \mathrm{~kg}$ & 43 & 4 & 2 & 1 & 50 \\
\hline & $>20 \mathrm{~kg}$ & 11 & 3 & 0 & 0 & 14 \\
\hline
\end{tabular}


$(n=24)$, incontinência urinária $(n=24)$, incontinência fecal $(n=17)$ e feridas de decúbito $(n=16)$ (Quadro 2). A incidência do aparecimento de complicações nos cães foi de 90,3\% (75/83) e nos gatos foi de 94,12\% (16/17). Todos os animais que não apresentaram complicações se recuperaram totalmente. Observou-se um índice de sobrevivência de 65,94\% (60/91) nos cães e gatos que apresentaram complicações. Dentre os animais que apresentaram complicações e sobreviveram, $35 \%$ (21/60) posteriormente apresentaram recuperação total, tanto da doença como das disfunções, enquanto que a maioria (65\%) permaneceu com sequelas neurológicas e incapacidade funcional.

A frequência da ocorrência das complicações foi de 91,3\% para as lesões medulares (63/69), 92,8\% para as lesões encefálicas (13/14), 80\% para as lesões do SNP (4/5) e 91,6\% para as lesões multifocais (11/12) (Quadro 3).

As principais etiologias nos animais que desenvolveram complicações foram trauma vertebromedular (TVM) (37,3\%), doença do disco intervertebral (DDIV) (14,2\%), doença inflamatória/infecciosa (12\%) e trauma cranioencefálico (TCE) $(9,8 \%)$ (Quadro 4).

\section{Trauma vertebromedular (TVM)}

Dos cães e gatos com lesão traumática na medula, 97,14\% apresentaram complicações (34/35) (Quadro 5). Dezoito animais apresentavam grau $\mathrm{V}$ de lesão medular (12 cães e seis gatos), quatorze apresentavam grau IV (nove cães e cinco gatos) e dois apresentavam grau II (dois cães).

Dezessete cães foram submetidos a tratamento conservativo (Mendes \& Arias 2012), com repouso, imobilização externa e medicações como analgesia (tramal, morfina ou infusão de fentanil + lidocaína + cetamina de acordo com a gravidade da dor), anti-inflamatórios não esteroidais (meloxican, por no máximo três dias) e antibióticos em caso de feridas ou contusão pulmonar. Não foram utilizados anti-inflamatórios esteroidais. Desses 17 pacientes, nove (60\%) não apresentaram recuperação e persistiram com complicações, como disfunções motoras $(n=6)$, atrofia muscular $(n=3)$, retenção urinária $(n=2)$, feridas por abrasão nos dígitos $(n=2)$, feridas de decúbito $(n=1)$, priapismo $(n=1)$, retenção fecal $(n=1)$, incontinência urinária $(n=1)$ e incontinência fecal $(n=1)$. Um cão com lesão cervical foi tratado com imobilização externa, entretanto apresentava sinais de trauma torácico concomitantemente,

Quadro 2. Complicações em 100 animais (cães e gatos) com doenças neurológicas atendidos no HV/UEL de 2013 a 2016

\begin{tabular}{|c|c|c|c|c|c|c|c|}
\hline Complicação & TVM & DDIV & $\begin{array}{c}\text { Doença inflamatória/ } \\
\text { infecciosa }\end{array}$ & TCE & SNP & Outros & TOTAL \\
\hline Atrofia & 9 & 3 & 4 & 0 & 4 & 12 & 32 \\
\hline Morte/ eutanásia & 8 & 2 & 5 & 5 & 0 & 11 & 31 \\
\hline Retenção urinária & 14 & 6 & 2 & 0 & 0 & 2 & 24 \\
\hline Incontinência urinária & 12 & 3 & 1 & 0 & 0 & 8 & 24 \\
\hline Incontinência fecal & 12 & 1 & 0 & 0 & 0 & 4 & 17 \\
\hline Feridas de decúbito & 5 & 1 & 3 & 0 & 0 & 7 & 16 \\
\hline Disfunções motoras & 9 & 3 & 1 & 0 & 0 & 1 & 14 \\
\hline Infecção urinária & 4 & 1 & 2 & 0 & 0 & 4 & 11 \\
\hline Sem complicações & 1 & 1 & 2 & 1 & 1 & 3 & 9 \\
\hline Assaduras & 2 & 0 & 0 & 0 & 0 & 5 & 7 \\
\hline Feridas por abrasão & 2 & 1 & 1 & 0 & 1 & 2 & 7 \\
\hline Complicações respiratórias & 1 & 2 & 1 & 2 & 0 & 1 & 7 \\
\hline Diminuição da consciência & 0 & 0 & 0 & 5 & 0 & 2 & 7 \\
\hline Retenção fecal & 3 & 1 & 0 & 0 & 0 & 2 & 6 \\
\hline Úlcera corneal & 0 & 0 & 0 & 5 & 0 & 0 & 5 \\
\hline Lesões em pênis & 3 & 0 & 1 & 0 & 0 & 1 & 5 \\
\hline Priapismo & 2 & 0 & 0 & 0 & 0 & 2 & 4 \\
\hline Contraturas musculares & 1 & 0 & 1 & 0 & 0 & 1 & 3 \\
\hline Cegueira cortical & 1 & 0 & 1 & 1 & 0 & 0 & 3 \\
\hline Parestesia & 1 & 0 & 0 & 0 & 0 & 2 & 3 \\
\hline Automutilação & 2 & 0 & 0 & 0 & 0 & 1 & 3 \\
\hline Vômito & 1 & 0 & 0 & 1 & 0 & 0 & 2 \\
\hline Alterações cognitivas/comportamentais & 0 & 0 & 0 & 1 & 0 & 0 & 1 \\
\hline Crises convulsivas & 0 & 0 & 1 & 0 & 0 & 0 & 1 \\
\hline Diarreia & 0 & 1 & 0 & 0 & 0 & 0 & 1 \\
\hline Megaesôfago & 1 & 0 & 0 & 0 & 0 & 0 & 1 \\
\hline Hipotermia & 1 & 0 & 0 & 0 & 0 & 0 & 1 \\
\hline Mielomalácia hemorrágica & 0 & 1 & 0 & 0 & 0 & 0 & 1 \\
\hline Infecção da ferida cirúrgica & 1 & 0 & 0 & 0 & 0 & 0 & 1 \\
\hline Complicações por uso de medicamentos & 0 & 0 & 1 & 0 & 0 & 0 & 1 \\
\hline
\end{tabular}

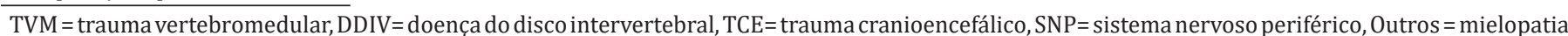
degenerativa, síndrome da cauda equina, hidrocefalia, infarto fibrocartilaginoso e neoplasia medular. 
vindo a morte 10 dias após o trauma. Um cão com síndrome lombossacra cranial grau $V$ veio a morte devido a um quadro de sepse e três cães foram submetidos à eutanásia devido à dificuldade de manejo e mau prognóstico.

Dois cães não se recuperaram após o tratamento cirúrgico de estabilização da coluna e ambos apresentavam lesão toracolombar grau V. Um permaneceu com incontinência urinária, incontinência fecal e atrofia muscular e o outro foi submetido à eutanásia devido à dificuldade de manejo.

Em relação aos 11 gatos com trauma vertebromedular, todos foram submetidos ao tratamento conservativo. As complicações presentes nos seis gatos que permaneceram com sequelas foram

Quadro 3. Localização das lesões em 83 cães e 17 gatos com doenças neurológicas atendidos no HV/UEL de 2013 a 2016

\begin{tabular}{|c|c|c|c|c|c|}
\hline \multirow{3}{*}{ Localização } & \multicolumn{2}{|c|}{ Cães } & \multicolumn{2}{|c|}{ Gatos } & \multirow{3}{*}{ TOTAL } \\
\hline & \multicolumn{4}{|c|}{ Complicações } & \\
\hline & Sim & Não & Sim & Não & \\
\hline Lesões Medulares & 52 & 6 & 11 & 0 & 69 \\
\hline Cervical & 11 & 2 & 0 & 0 & 13 \\
\hline Cervicotorácica & 4 & 1 & 0 & 0 & 5 \\
\hline Toracolombar & 20 & 0 & 4 & 0 & 24 \\
\hline \multicolumn{6}{|l|}{ Lombossacra } \\
\hline Cranial & 12 & 0 & 4 & 0 & 16 \\
\hline Caudal & 5 & 3 & 3 & 0 & 11 \\
\hline Lesões Encefálicas & 10 & 0 & 3 & 1 & 14 \\
\hline Córtex & 7 & 0 & 1 & 0 & 8 \\
\hline Tronco encefálico & 3 & 0 & 2 & 1 & 6 \\
\hline Lesões do SNP & 4 & 1 & 0 & 0 & 5 \\
\hline Nervo perfiférico & 3 & 0 & 0 & 0 & 3 \\
\hline Junção neuromuscular & 1 & 1 & 0 & 0 & 2 \\
\hline Multifocal/ Difusa & 9 & 1 & 2 & 0 & 12 \\
\hline
\end{tabular}

Quadro 4. Etiologias das afecções neurológicas em 83 cães e 17 gatos atendidos no HV/UEL de 2013 a 2016

\begin{tabular}{lccccc}
\hline \multirow{2}{*}{\multicolumn{1}{c}{ Etiologia }} & \multicolumn{3}{c}{ Cães } & \multicolumn{3}{c}{ Gatos } & \\
\cline { 2 - 5 } & \multicolumn{4}{c}{ Tomplicações } \\
\cline { 2 - 5 } & Sim & Não & Sim & Nãon & \\
\hline Trauma Vertebromedular & 23 & 1 & 11 & 0 & 35 \\
Doença do disco intervertebral & 13 & 1 & 0 & 0 & 14 \\
Doença Inflamatória/ infecciosa & 10 & 2 & 1 & 0 & 13 \\
Trauma Cranioencefálico & 6 & 0 & 3 & 1 & 10 \\
Inconclusivo & 4 & 2 & 1 & 0 & 7 \\
Síndrome da Cauda Equina & 3 & 1 & 0 & 0 & 4 \\
Mielopatia degenerativa & 3 & 0 & 0 & 0 & 3 \\
Neoplasia & 3 & 0 & 0 & 0 & 3 \\
Hidrocefalia & 2 & 0 & 0 & 0 & 2 \\
Infarto fibrocartilaginoso & 2 & 0 & 0 & 0 & 2 \\
Lesão em nervo espinhal & 2 & 0 & 0 & 0 & 2 \\
Polineuropatia motora periférica & 1 & 1 & 0 & 0 & 2 \\
Avulsão do plexo braquial & 1 & 0 & 0 & 0 & 1 \\
Lesão cortico-talâmica & 1 & 0 & 0 & 0 & 1 \\
pós-parada cardiorrespiratória & & & & & \\
Alteração congênita em coluna & 1 & 0 & 0 & 0 & 1
\end{tabular}

retenção urinária $(n=4)$, disfunções motoras $(n=3)$, atrofia muscular $(n=2)$ e retenção fecal $(n=1)$. Um gato com lesão lombossacra cranial grau $\mathrm{V}$ foi submetido à eutanásia devido à dificuldade no manejo e um gato com síndrome multifocal veio a morte devido à presença de piotórax decorrente de lesão por mordedura.

\section{Doença do disco intervertebral (DDIV)}

A frequência de aparecimento de complicações nos animais com DDIV foi de 92,86\% (13/14) (Quadro 6). Quatro cães apresentavam DDIV cervical (três com grau I e um com grau III), um apresentava DDIV cervicotorácico grau II e oito apresentavam DDIV toracolombar (cinco com grau V e três com grau IV). Entre os sete animais com DDIV toracolombar que foram submetidos à hemilaminectomia para descompressão medular, três permaneceram com sequelas como disfunções motoras $(n=3)$, feridas por abrasão $(n=2)$, retenção urinária e infecção urinária, três apresentaram recuperação e um cão foi submetido à eutanásia devido a suspeita de mielomalácia hemorrágica progressiva (MHP). A média de tempo de recuperação nos três cães que apresentaram recuperação total após a cirurgia foi de um mês.

Dos quatro cães com DDIV cervical (dois com grau I e dois com grau III) submetidos à slot cervical, um apresentou dificuldade respiratória após a cirurgia e veio a morte e um apresentou complicação decorrente de hemorragia transoperatória, ocorrendo melhora do quadro após a transfusão sanguínea. Um animal com lesão medular grau III permaneceu

Quadro 5. Localização da lesão, tratamento e evolução em 23 cães e 11 gatos com complicações decorrentes de trauma vertebromedular atendidos no HV/UEL de 2013 a 2016

\begin{tabular}{|c|c|c|c|c|c|}
\hline $\begin{array}{c}\text { Localização da } \\
\text { lesão/Tratamento }\end{array}$ & Recuperação & Disfunção & Eutanásia & Morte & TOTAL \\
\hline \multicolumn{6}{|l|}{ Cães } \\
\hline \multicolumn{6}{|l|}{ Cervical } \\
\hline Conservativo & 0 & 0 & 0 & 1 & 1 \\
\hline \multicolumn{6}{|l|}{ Toracolombar } \\
\hline Conservativo & 1 & 5 & 1 & 0 & 7 \\
\hline Cirúrgico & 0 & 1 & 1 & 0 & 2 \\
\hline \multicolumn{6}{|l|}{ Lombossacra cranial } \\
\hline Conservativo & 1 & 3 & 2 & 1 & 7 \\
\hline Cirúrgico & 2 & 0 & 0 & 0 & 2 \\
\hline \multicolumn{6}{|l|}{ Lombossacra caudal } \\
\hline Cirúrgico & 2 & 0 & 0 & 0 & 2 \\
\hline \multicolumn{6}{|l|}{ Multifocal } \\
\hline Conservativo & 1 & 1 & 0 & 0 & 2 \\
\hline TOTAL & 7 & 10 & 4 & 2 & 23 \\
\hline \multicolumn{6}{|l|}{ Gatos } \\
\hline \multicolumn{6}{|l|}{ Toracolombar } \\
\hline Conservativo & 1 & 3 & 0 & 0 & 4 \\
\hline \multicolumn{6}{|l|}{ Lombossaca cranial } \\
\hline Conservativo & 0 & 2 & 1 & 0 & 3 \\
\hline \multicolumn{6}{|l|}{ Lombossacra caudal } \\
\hline Conservativo & 2 & 1 & 0 & 0 & 3 \\
\hline \multicolumn{6}{|l|}{ Multifocal } \\
\hline Conservativo & 0 & 0 & 0 & 1 & 1 \\
\hline TOTAL & 3 & 6 & 1 & 1 & 11 \\
\hline
\end{tabular}


Quadro 6. Localização da lesão, tratamento e evolução em 13 cães com complicações decorrentes de doença do disco intervertebral (DDIV) atendidos no HV/UEL de 2013 a 2016

\begin{tabular}{|c|c|c|c|c|c|c|}
\hline Localização da lesão & Tratamento & Recuperação & Disfunção & Eutanásia & Morte & TOTAL \\
\hline \multicolumn{7}{|l|}{ Cervical } \\
\hline & Conservativo & 0 & 0 & 0 & 0 & 0 \\
\hline & Cirúrgico & 2 & 1 & 0 & 1 & 4 \\
\hline \multicolumn{7}{|l|}{ Cervicotorácica } \\
\hline & Conservativo & 1 & 0 & 0 & 0 & 1 \\
\hline & Cirúrgico & 0 & 0 & 0 & 0 & 0 \\
\hline \multicolumn{7}{|l|}{ Toracolombar } \\
\hline & Conservativo & 1 & 0 & 0 & 0 & 1 \\
\hline & Cirúrgico & 3 & 3 & 1 & 0 & 7 \\
\hline TOTAL & & 7 & 4 & 1 & 1 & 13 \\
\hline
\end{tabular}

com disfunção motora por 5 meses, apresentando melhora posteriormente. Um cão com DDIV cervicotorácica grau II, que apresentava apenas atrofia muscular como complicação, foi submetido ao tratamento conservativo apresentando recuperação total.

\section{Doença inflamatório-infecciosa}

Foram acompanhados 13 casos de doença inflamatória/ infecciosa, como cinomose ( 5 cães), suspeita de meningoencefalite granulomatosa ( 6 cães), discoespondilite (1 cão) e encefalite (um felino). 84,61\% dos pacientes apresentaram complicações (dez cães e um gato). Em cinco animais não houve recuperação e as disfunções persistiram, como feridas de decúbito $(n=3)$, retenção urinária $(n=3)$, infecção urinária $(n=2)$, atrofia muscular $(n=2)$, efeitos colaterais por uso de corticoides $(n=1)$ e disfunção motora $(n=1)$; quatro foram submetidos à eutanásia devido ao prognóstico ruim; um veio a morte devido à piora do quadro neurológico e um apresentou recuperação total, tanto da doença como das complicações.

\section{Trauma cranioencefálico (TCE)}

A frequência de aparecimento de complicações nos animais com TCE foi de 90\% (9/10). As principais complicações encontradas foram diminuição do nível de consciência $(n=5)$ e úlcera corneal $(n=5)$. Em relação aos cães, dois foram submetidos à eutanásia em menos de um mês devido à presença de sequelas; dois vieram a morte (um por piora do quadro um dia após o trauma e outro por atropelamento seis meses após o trauma) e dois permaneceram com úlcera corneal e dificuldade visual. Já em relação aos gatos, dois permaneceram com sequelas como cegueira cortical e úlcera corneal e um veio a morte 18 dias após o trauma por parada cardiorrespiratória na anestesia para limpeza de ferida. Nenhum animal com TCE apresentou recuperação total.

\section{Sistema nervoso periférico (SNP)}

Dois cães que foram submetidos à osteossíntese de pelve permaneceram com monoplegia devido à provável lesão traumática no nervo ciático, ocorrendo atrofia muscular no membro acometido. Ambos foram submetidos à amputação do membro. Um cão com avulsão do plexo braquial apresentou atrofia muscular e feridas por abrasão no membro, que foi amputado. Um cão com suspeita de polineuropatia motora periférica desenvolveu atrofia muscular em todos os membros. No entanto, após o tratamento, apresentou recuperação total.

\section{Outras etiologias}

Suspeitou-se de mielopatia degenerativa em três animais; um com síndrome toracolombar; um com síndrome lombossacra cranial e um com síndrome difusa (toracolombar e lombossacra cranial). Todos desenvolveram complicações como feridas de decúbito, incontinência urinária, incontinência fecal, assaduras, contraturas musculares e atrofia muscular. Todos foram submetidos à eutanásia devido ao mau prognóstico e à dificuldade no manejo. A sobrevida máxima desses animais foi de cinco meses e a mínima foi de um mês após o atendimento.

Quatro cães apresentaram síndrome da cauda equina, entre eles, três (75\%) desenvolveram complicações. Todos foram primeiramente submetidos ao tratamento conservativo e posteriormente ao cirúrgico. Observou-se a presença de atrofia muscular, dor excessiva e parestesia na região do nervo ciático e na base da cauda, incontinência urinária, infecção urinária e incontinência fecal. Um animal apresentou recuperação total, um foi submetido à amputação da cauda e um permaneceu com incontinência urinária e cistite recorrente.

Dois cães diagnosticados com hidrocefalia apresentavam diminuição do nível de consciência, um animal veio a morte e um permaneceu com disfunções cognitivas/comportamentais.

Suspeitou-se de infarto fibrocartilaginoso em dois animais, ambos com síndrome lombossacra cranial. As complicações observadas foram retenção ou incontinência urinária, infecção urinária, incontinência fecal, assaduras, feridas de decúbito e atrofia muscular. Após o tratamento conservativo, um apresentou recuperação total e um permaneceu com disfunção motora, feridas de decúbito, retenção urinária e infecção urinária.

Em três animais foi diagnosticada neoplasia medular e todos desenvolveram complicações. Um apresentava síndrome cervical, um cervicotorácica e um toracolombar. Observou-se a ocorrência de incontinência urinária, feridas de decúbito, atrofia muscular, retenção fecal, feridas por abrasão em dígitos, priapismo e assaduras. Todos foram submetidos à eutanásia devido à progressão do quadro e mau prognóstico. Um animal diagnosticado com alteração congênita em coluna apresentava escoliose, atrofia muscular e dificuldade de locomoção. 0 animal foi tratado com fisioterapia, uso de colete para manter o alinhamento vertebral e acupuntura, entretanto não houve recuperação funcional. 


\section{Análise estatística}

A curva de sobrevivência global, sem considerar covariáveis, com os respectivos intervalos de $95 \%$ de confiança para $t$ tal que $0 \leq t \leq 30$, pode ser visualizada na Figura 1. 0 tempo mediano e médio de vida dos cães e gatos com complicações foram estimados, respectivamente, em 2 e 7 meses, sendo que as causas de morte incluíram piora do quadro neurológico ou opção pela eutanásia e em três animais a morte ocorreu devido à presença de lesões concomitantes em outros sistemas.

Por meio da análise de Kaplan-Meier foram obtidas curvas de sobrevivência para as covariáveis sexo, idade e peso (Figura 2), ao nível de significância de 10\%. Observou-se que quanto maior o peso e a idade dos animais, menor é o tempo de sobrevida. Quanto à covariável sexo, no teste logrank não houve diferenças estatísticas significativas entre as curvas de sobrevivência (valor $p=0,428$ ).

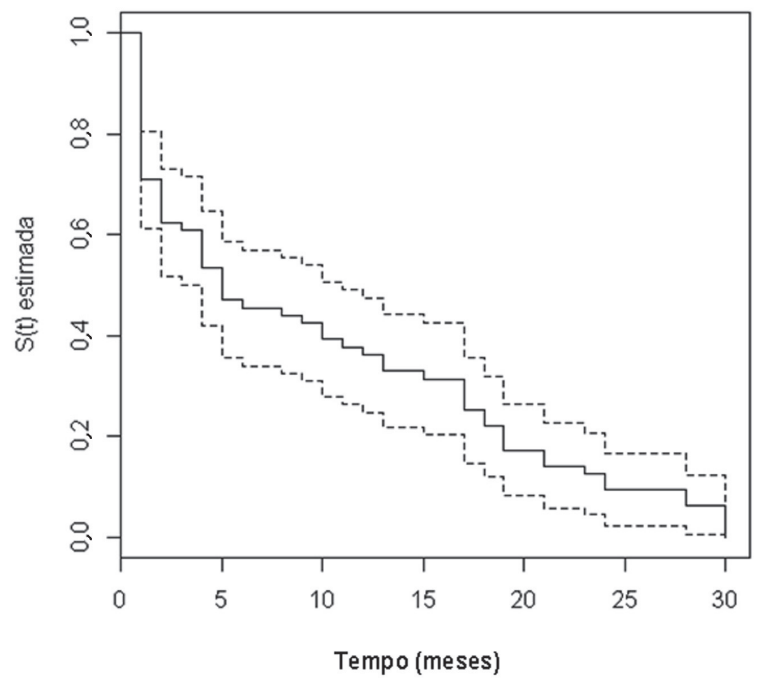

Fig.1. Curva de sobrevivência global e respectivos intervalos de 95\% de confiança, obtidos a partir do estimador de Kaplan-Meier para os dados do estudo.

\section{DISCUSSÃO}

No presente estudo, $91 \%$ dos cães e gatos apresentaram complicações, sendo que as principais foram atrofia muscular, distúrbios da micção/defecação e feridas de decúbito. A alta incidência de complicações se deve ao fato de que doenças neurológicas afetam vários outros órgãos e sistemas, pelo comprometimento das funções motoras, sensoriais e autonômicas (Sims et al. 2015), além de ocorrerem comorbidades, principalmente nas afecções de etiologia traumática (Mendes \& Arias 2012). A prevenção das lesões secundárias é fundamental para a recuperação do paciente neurológico (Sharp \& Wheeler 2005a) e embora os tutores tenham sido orientados quanto ao manejo, prevenção e tratamento das complicações, pode haver dificuldade em compreendê-las ou segui-las corretamente. 0 manejo do paciente com problema neurológico pode ser muito trabalhoso (Sharp \& Wheeler 2005a), podendo haver muita sobrecarga física e mental sobre o cuidador (Freeman et al. 2013).

As alterações neurológicas decorrentes de lesões medulares variam desde leve paraparesia até paraplegia (Freeman et al. 2013), podendo resultar na perda do tônus e massa muscular, contraturas musculares e alteração na mobilidade das articulações (Sharp \& Wheeler 2005a). Tais condições foram evidenciadas no presente estudo, onde a principal complicação foi atrofia muscular. A fisioterapia, associada aos tratamentos clínico ou cirúrgico, possui um papel importante para a recuperação desses pacientes (Lorenz \& Kornegay 2006). 0 programa de fisioterapia quando bem projetado, pode diminuir o tempo de hospitalização, prevenir doenças secundárias e auxiliar no estado mental dos pacientes (Jerram et al. 1997, Sharp \& Wheeler 2005a). Na maioria dos casos foi realizado o encaminhamento dos animais para programas de fisioterapia externos ao Hospital de realização do estudo, bem como foram realizadas orientações de cuidados ao proprietário, mas constatou-se que muitos tutores possuíam limitação financeira e de tempo para seguir essas recomendações. Embora no presente trabalho não tenha sido estudado a
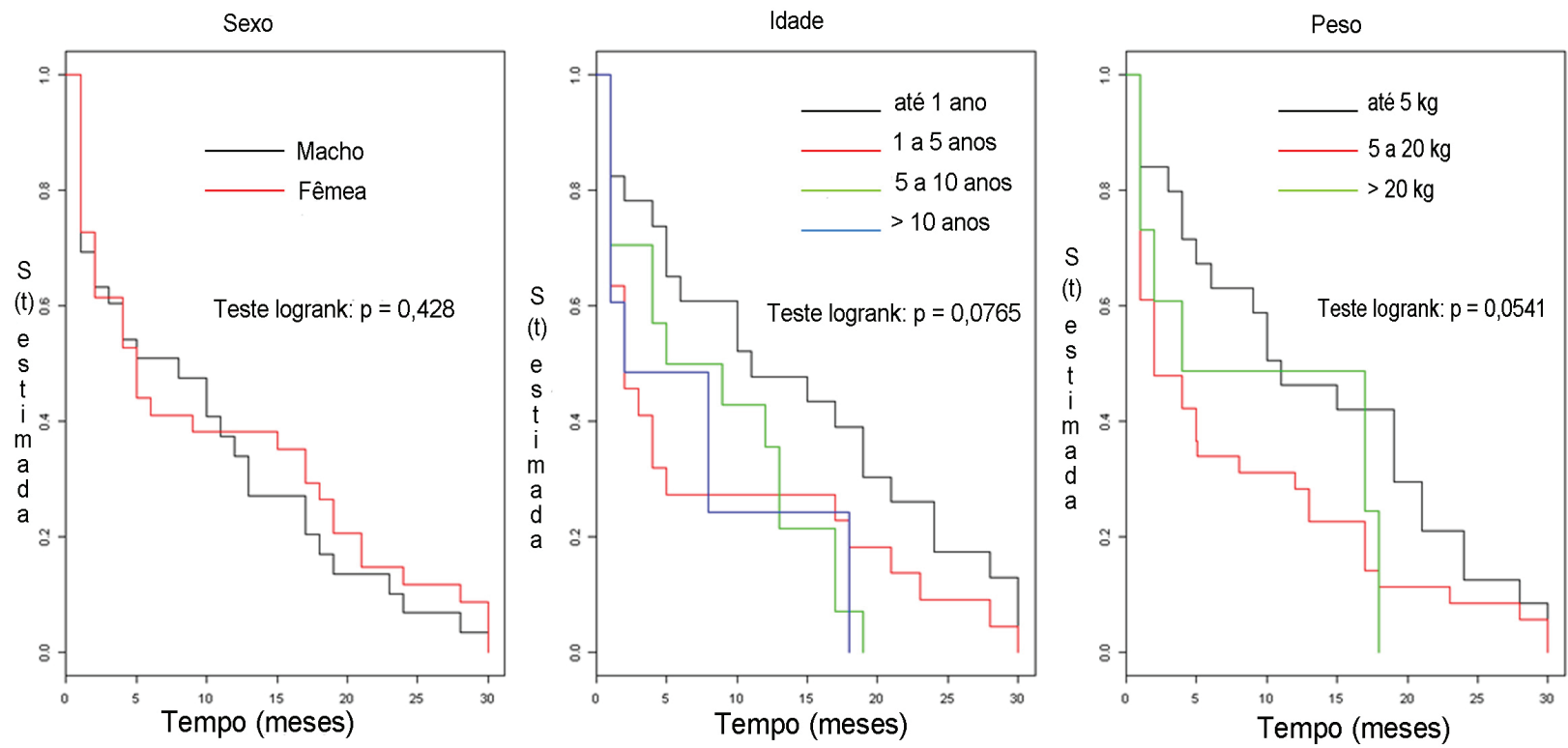

Fig.2. Curvas de sobrevivência estimadas pelo método de Kaplan-Meier para cada covariável e respectivos valores $p$ associados ao teste logrank. 
capacidade dos tutores em avaliar a qualidade de vida dos pacientes (Levine et al. 2008) ou a motivação dos mesmos em realizar os cuidados (Freeman et al. 2013), é comprovado que existem muitos problemas emocionais, financeiros e sociais envolvidos nos cuidados de animais com afecções neurológicas que são subestimados (Freeman et al. 2013).

Como observado no presente estudo, os distúrbios da micção, consideradas as mais graves, totalizaram 24\%. Essas alterações são comuns nos animais com problemas neurológicos e podem ser causados pela atividade anormal do músculo detrusor, dos esfíncteres ou de ambos (Lorenz \& Kornegay 2006). A falha do esvaziamento vesical pode causar problemas graves como cistite, atonia vesical, hidroureter, hidronefrose, pielonefrite e ruptura iatrogênica de vesícula urinária (Nicoll \& Remedios 1995, Jerram et al. 1997). Freeman et al. (2013) constataram que os tutores passaram cerca de 15 minutos por dia auxiliando no manejo da micção de animais com lesões medulares crônicas. Os objetivos deste manejo são o esvaziamento vesical periódico e a prevenção da ocorrência de urina residual, a fim de reduzir o risco de infecção urinária (Sharp \& Wheeler 2005a). Na experiência dos autores do presente estudo, mesmo após a orientação sobre manejo da micção, os tutores nem sempre realizaram o mesmo de forma correta, pois ao observarem a ocorrência de gotejamento de urina, entendem que o animal já é capaz de urinar sozinho e interrompem este manejo por conta própria. 0 gotejamento de urina ocorre quando a vesícula urinária retém urina, resultando em extravasamento ou incontinência por retenção. Na medicina humana há vários estudos que demonstram que a maneira como os clínicos interagem com os clientes interfere significativamente no cumprimento das recomendações de tratamento e na recuperação dos pacientes, sendo que o mesmo foi constatado em veterinária (Bonvicini \& Cornell 2007). Assim, os veterinários não devem negligenciar a importância da comunicação com o tutor, sendo recomendado inclusive a entrega de orientações por escrito (Sims et al. 2015).

Outra complicação observada nos animais do presente estudo foi o desenvolvimento de feridas de decúbito, frequentes em pacientes com doenças neurológicas, em decorrência da impossibilidade de mudar a posição corporal devido à paraplegia/tetraplegia (Sharp \& Wheeler 2005a) ou da lesão de nervos periféricos (Lorenz et al. 2011b). 0 principal fator causal é a pressão sobre as proeminências ósseas, resultando em obstrução vascular, isquemia e necrose celular (Nicoll \& Remedios 1995). 0 tratamento das úlceras visa redistribuir a pressão por meio da mudança frequente do decúbito, repouso em local acolchoado, massagem e realização de curativos adequados. Quando possível, o paciente pode ser elevado com ajuda de suspensório comercial ou carrinho de rodas (Nicoll \& Remedios 1995, Jerram et al. 1997, Behr \& Green 2012). Freeman et al. (2013) constataram em um estudo com cães paraplégicos decorrente de lesão medular há mais de nove meses, que os tutores passaram de 0 a 60 minutos ao dia (média quatro minutos) cuidando do manejo da pele de animais com feridas por decúbito.

\section{Trauma vertebromedular}

Uma das principais causas de lesão neurológica em pequenos animais é o trauma vertebromedular (Jeffery 2010), que pode levar à incapacidade permanente ou até a morte, devido a alterações motoras, sensoriais e presença de lesões a outros sistemas orgânicos (Arias et al. 2007, Olby 2010). As fraturas e luxações podem causar graus variados de disfunção neurológica, desde dor até plegias (Grasmueck \& Steffen 2004, Mendes \& Arias 2012, Araújo et al. 2015), sendo que vários estudos avaliaram a sobrevivência e evolução do quadro (Grasmueck \& Steffen 2004, Mendes \& Arias 2012, Araújo et al. 2015), mas poucos avaliaram a ocorrência de complicações. No presente estudo, observou-se que $76 \%$ dos casos de cães e gatos com lesões traumáticas na medula sobreviveram, entretanto $61 \%$ desses permaneceram com sequelas, sendo as principais disfunções motoras, atrofia muscular e retenção urinária. Segundo Jeffery (2010), as complicações relacionadas ao trauma vertebromedular ocorrem principalmente devido ao desuso dos membros e às disfunções do controle da micção, conforme constatado no presente estudo.

Oito animais não sobreviveram (cinco foram submetidos à eutanásia e três vieram a morte), sendo que a causa da morte nesses pacientes foi a presença de lesões concomitantes em outros sistemas e a razão pela eutanásia foi o prognóstico ruim e a dificuldade de manejo. No trauma vertebromedular a morte pode estar relacionada à presença de lesões concomitantes, que ocorrem frequentemente em animais que sofrem trauma externo (Grasmueck \& Steffen 2004, Jeffery 2010), ocorrência de mielomalácia e opção do proprietário (Grasmueck \& Steffen 2004, Mendes \& Arias 2012), conforme observado no presente estudo. Um estudo realizado por Mendes \& Arias (2012) em animais com traumatismo na medula espinhal constatou que $47,4 \%$ dos animais possuíam lesões sistêmicas concomitantes e a mais comum foi o trauma torácico, condição que também foi observada no presente estudo.

Olby et al. (2003) avaliaram a evolução de cães com lesão traumática grave no segmento medular toracolombar, constatando que o prognóstico para a recuperação da locomoção nesses pacientes é reservado, o que está de acordo com os achados do presente estudo, no qual observou-se que dois cães com lesão toracolombar grau $V$ submetidos ao tratamento cirúrgico não apresentaram retorno da função motora, sendo recomendado o uso de carrinho de rodas para esses pacientes, a fim de melhorar a qualidade de vida e reduzir os riscos de complicações (Sims et al. 2015).

Como observado no presente estudo, a junção toracolombar foi o local mais acometido no trauma vertebromedular (Jeffery 2010). Esta localização, associada à perda da sensibilidade dolorosa profunda, segundo Mendes \& Arias (2012), foram os fatores mais relacionados à eutanásia ou mortalidade dos animais. Em relação à região lombossacra cranial, o índice de sobrevivência é semelhante nos dois estudos, porém no presente estudo, constatou-se a permanência de complicações em cinco pacientes, tais como disfunções motoras e distúrbios do controle da micção.

A principal sequela observada nos gatos que não apresentaram recuperação foi retenção urinária, complicação também encontrada com frequência de $76 \%$ no estudo de Grasmueck \& Steffen (2004), que avaliaram a taxa de sobrevivência e a evolução de gatos com lesões traumáticas nos segmentos torácicos e lombares.

Segundo Jeffery (2010), o TVM em veterinária, para muitos pacientes, apresenta melhor prognóstico do que na medicina humana, nos quais o tempo de internamento pode chegar a 
um ano, entretanto deve-se estar preparado para um longo tratamento, realizando um programa de fisioterapia adequado ao tipo de tratamento escolhido, seja conservativo ou cirúrgico.

\section{Doença do disco intervertebral}

A DDIV é uma das principais afecções neurológicas responsável por produzir disfunções motoras e sensoriais em cães (Lorenz \& Kornegay 2006). Muitos estudos foram realizados com o objetivo de avaliar os fatores prognósticos associados à recuperação funcional desses animais, e os resultados continuam sendo contraditórios, sendo os principais fatores envolvidos na recuperação o grau de lesão medular e a presença de sensibilidade dolorosa profunda (Davis \& Brown 2002, Amsellem et al. 2003, Olby et al. 2003, Ruddle et al. 2006, Hillman et al. 2009, Jeffery et al. 2013, Jeffery et al. 2016).

No presente estudo, dois animais com DDIV que foram tratados conservativamente (um com lesão cervicotorácica grau II e um com lesão toracolombar grau IV) apresentaram recuperação total. Tal resultado está de acordo com os achados do estudo de Levine et al. (2007), que constataram que o manejo médico também pode levar ao sucesso na recuperação de cães com DDIV toracolombar.

Segundo Olby et al. (2003), cães com paraplegia grau V devido à DDIV possuem melhor prognóstico do que cães com lesão medular decorrente de trauma, o que condiz com os resultados encontrados no presente estudo, pois o índice de sobrevivência dos animais com DDIV grau $\mathrm{V}$ foi de $80 \%$.

Os cães com DDIV toracolombar grau V submetidos à hemilaminectomia apresentaram índices de recuperação semelhante a outros estudos, que referem a ocorrência de melhora entre 0 e $76 \%$ (Brisson 2010). Entretanto, a maioria dos estudos considera o evento "retorno da locomoção" como bom resultado, não citando a ocorrência de outras complicações além de mielomalácia hemorrágica, infecção urinária e opção por eutanásia (Olby et al. 2003, Laitinen \& Puerto 2005, Jeffery et al. 2016).

No presente estudo, a infecção urinária foi uma das principais complicações nos animais com DDIV toracolombar submetidos ao tratamento cirúrgico. A principal causa de infecção urinária é a retenção urinária, decorrente da espasticidade dos esfíncteres, mais comum na lesão do tipo NMS (Jeffery 2010), o que contribui para que permaneça volume residual na vesícula urinária, podendo ainda ocorrer pielonefrite por refluxo ureteral (Sharp \& Wheeler 2005a). Em cães com lesão medular TL por trauma ou DDIV, foi observado que dentre os animais que recuperaram a função motora e sensibilidade profunda, 32\% mantiveram-se incontinentes urinários e 24\% a 38\% apresentaram infecção do trato urinário em um período de até três meses após a cirurgia, sendo constatado maior risco de ocorrência do problema em fêmeas, cães paraplégicos e que necessitam de assistência para o esvaziamento vesical (Stiffler et al. 2006, Bubenik \& Hosgood 2008, Olby et al. 2010). Poucos tutores são capazes de detectar os sinais clínicos de infecção, e há uma alta porcentagem de infecções urinárias ocultas, pois os sinais clássicos de disúria não estão presentes em cães paraplégicos, evidenciando a importância da realização de culturas em todos os cães paraplégicos (Olby et al. 2010).

Um animal foi submetido à eutanásia durante o procedimento cirúrgico devido à presença de alterações macroscópicas sugestivas de mielomalácia hemorrágica progressiva. De acordo com Olby et al. (2003), espera-se uma incidência de MHP de aproximadamente $10 \%$ em cães com lesões medulares graves devido à DDIV, o que também está de acordo com os resultados de Jeffery et al. (2016), que constatou que $13 \%$ dos cães desenvolveram sinais sugestivos de MHP no período pós operatório. 0 prognóstico para esses pacientes é ruim e a morte pode ocorrer devido a paralisia respiratória (Amsellem et al. 2003), sendo recomendada a eutanásia, a fim de evitar sofrimentos adicionais (Sharp \& Wheeler 2005b).

Rossmeisl et al. (2013) descreveram a incidência de 9,9\% de eventos adversos associados ao procedimento cirúrgico de slot ventral para descompressão medular, incluindo complicações relacionadas à hemorragia intraoperatória e hipoventilação neurogênica, que foram as causas das complicações constatadas no presente estudo. Outras complicações que podem estar associadas a essa abordagem cirúrgica incluem síndrome de Horner, hipotensão, arritmias cardíacas, instabilidade e subluxação vertebral (Slatter 2003). Beal et al. (2001) verificaram a ocorrência de complicações respiratórias em cães submetidos ao tratamento cirúrgico de doenças cervicais constatando que cães com lesões entre a segunda e a quarta vértebra cervical possuem maior risco de desenvolver hipoventilação no período pós-operatório, além de possuírem menor chance de sobrevivência do que cães submetidos à cirurgia de descompressão toracolombar (Lexmaulová et al. 2008, Posner et al. 2014).

\section{Doenças inflamatórias/infecciosas}

A principal causa de morte em pequenos animais é a ocorrência de doenças infecciosas (Bentubo et al. 2007, Fighera et al. 2008). 0 prognóstico das doenças inflamatórias do SNC é ruim, sendo que a maioria dos animais não sobrevivem (LeCouteur 2011). Tais resultados estão de acordo com o observado no presente estudo, pois grande parte dos animais com estas afecções não sobreviveu, e entre os que sobreviveram, a maioria permaneceu com disfunções como feridas de decúbito e retenção urinária.

\section{Trauma cranioencefálico}

Embora cães e gatos possuam uma habilidade marcante de compensar a perda do tecido cerebral após trauma craniano (Dewey 2000, Sande \& West 2010), lesões graves estão associadas a alto índice de mortalidade (Dewey 2000), que ocorre principalmente devido à baixa perfusão e oxigenação cerebral (Garosi \& Adamantos 2011, Sharma \& Holowaychuk 2015). Além disso, nos cães que sobrevivem pode não haver capacidade funcional como animais de estimação, pois vários pacientes apresentam sequelas neurológicas importantes (Vianna \& Arias 2013), conforme constatado no presente estudo, evidenciando que o prognóstico para esses pacientes é considerado de reservado a mau (Dewey 2000).

Segundo Dewey (2000) e Sande \& West (2010), as principais complicações secundárias ao TCE podem incluir coagulopatias, pneumonia, alterações eletrolíticas, sepse e convulsões. Entretanto, no presente estudo, os cães e gatos que sobreviveram apresentaram como principal complicação úlceras corneanas, decorrente de autotraumatismo ao pressionarem a cabeça contra paredes. Lesão traumática na córnea é provavelmente a causa mais comum de úlcera corneal em pequenos animais, sendo que lesões crônicas e profundas podem se tornar permanentes e até levar à cegueira (Millichamp et al. 1990). 
Um animal do presente estudo veio a morte ao ser submetido à anestesia. De acordo com Armitage-Chan et al. (2007), muitos agentes anestésicos possuem potencial para causar lesão adicional no tecido nervoso, embora outros sejam protetores por diminuir o metabolismo cerebral. Entretanto, muitas vezes a sobrevivência do animal depende de procedimentos que necessitam de anestesia, devendo-se pesar o risco e o benefício das decisões (Armitage-Chan et al. 2007).

Predizer o prognóstico para animais com TCE muitas vezes pode ser difícil (Dewey 2000), sendo importante conscientizar o tutor de que o objetivo principal do manejo nesses pacientes é a recuperação funcional à um nível aceitável visado a manutenção da qualidade de vida (Sande \& West 2010).

\section{Sistema nervoso periférico}

No SNP as principais complicações estão relacionadas ao desenvolvimento de atrofia muscular, contraturas e ulcerações (De Lahunta \& Glass 2015b). Algumas afecções, como a lesão ao nervo ciático ou avulsão do plexo braquial, resultam em atrofia muscular neurogênica grave e rápida, e a infecção, abrasão do membro mal posicionado ou comprometimento da circulação local podem ainda originar uma ferida crônica que não cicatriza ou que ulcera (Lorenz et al. 2011b). De acordo com Lorenz \& Kornegay (2006), devido à sua localização anatômica, o nervo ciático está particularmente sujeito à lesão por fraturas pélvicas, embora também seja comum a iatrogenia durante a realização da osteossíntese (Forterre et al. 2007). Tais lesões podem resultar em monoparesia grave e automutilação do membro (Lorenz \& Kornegay 2006). Em relação aos cães e gatos do presente estudo, nenhum apresentou recuperação da função motora e ambos desenvolveram atrofia muscular e ulcerações, sendo então realizada a amputação.

\section{Outras etiologias}

A mielopatia degenerativa é caracterizada inicialmente por paraparesia espástica, que progride lentamente para paraplegia e eventualmente, dependendo do tempo que os animais são mantidos, evolui para tetraparesia flácida (Coates \& Wininger 2010). Os proprietários optam pela eutanásia quando os cães não são mais capazes de sustentar seu peso e necessitam de assistência para se locomoverem. Nos estágios tardios da doença pode haver a perda grave e generalizada de massa muscular, além de incontinência fecal e urinária (Coates \& Wininger 2010), que foram as principais complicações observadas nos cães e gatos do presente estudo. Kathmann et al. (2006) realizou um trabalho avaliando a influência da fisioterapia intensiva no tempo de sobrevivência de animais com mielopatia degenerativa, (Sims et al. 2015), constatando esses pacientes sobrevivem por mais tempo e preservam a locomoção por períodos maiores do que animais que não são submetidos à essa intensidade de fisioterapia, que foi a opção dos tutores dos pacientes do presente estudo.

Em relação aos animais com síndrome da cauda equina, 75\% apresentaram complicações e todos foram submetidos ao tratamento médico antes do tratamento cirúrgico. 0 tratamento conservativo auxilia no controle da dor, que é uma complicação presente em muitos pacientes (Meij \& Bergknut 2010). Em um estudo com cães com estenose lombossacra submetidos ao tratamento médico (atividade restrita e uso de anti-inflamatórios não esteroidais por um período de 4 a 6 semanas), observou-se um índice de 55\% de sucesso, concluindo-se que o prognóstico para cães com síndrome da cauda equina tratados conservativamente é bom (De Decker et al. 2014). 0 tratamento cirúrgico é indicado para cães com dor moderada a severa que não responde ao tratamento médico, presença de automutilação e disfunções neurológicas mais severas (Indrieri 1988, Meij \& Bergknut 2010, De Decker et al. 2014), que era o caso dos pacientes do presente estudo. Geralmente o prognóstico para cães submetidos à intervenção cirúrgica é bom à excelente (Indrieri 1988, De Decker et al. 2014). Entretanto, no presente estudo, um animal permaneceu com incontinência urinária após a cirurgia. A incontinência urinária e/ou fecal é relatada com alguma frequência em cães com estenose lombossacra (Indrieri 1988, Meij \& Bergknut 2010), e segundo De Decker et al. (2014), esses pacientes devem ser submetidos ao tratamento cirúrgico o quanto antes, para otimizar as chances de recuperação da micção. Segundo De Risio et al. (2001) em cães com estenose lombossacra submetidos à laminectomia dorsal, a presença e a duração de incontinência urinária antes da cirurgia são os fatores que mais influenciam negativamente no prognóstico. Provavelmente esse tenha sido o motivo pelo qual o animal que apresentava incontinência urinária antes da cirurgia não apresentou recuperação. Além da incontinência urinária, o animal também apresentava cistite recorrente. Segundo Barcellos et al. (2007), para o sucesso do tratamento de cães com cistite neurogênica deve-se considerar ainda a sensibilidade microbiana e o pH urinário para atuação do antimicrobiano.

Os sinais clínicos da hidrocefalia congênita são observados pelos tutores durante os primeiros meses de vida (Coates et al. 2006, Thomas 2010) e incluem alterações de comportamento, disfunção cognitiva e dificuldade de aprendizagem (Coates et al. 2006), como observado no presente estudo. 0 curso da doença é variável e as disfunções podem progredir, permanecer estáveis ou melhorar após 1 ou 2 anos de idade (Thomas 2010). No presente estudo, nenhum dos dois animais apresentou melhora dos sinais. 0 tratamento instituído mais comumente nesses animais é conservativo e tem apenas função paliativa (Coates et al. 2006).

Suspeitou-se de infarto fibrocartilaginoso em dois animais, ambos com síndrome lombossacra cranial. 0 infarto fibrocartilaginoso é caracterizado por sinais neurológicos medulares variados, de início agudo, sem hiperpatia e de caráter não progressivo (Nakamoto et al. 2008, 2009). Nem sempre há recuperação de cães com infarto fibrocartilaginoso no segmento medular L4-S3 (Nakamoto et al. 2009), o que foi observado também no presente estudo, e provavelmente lesões nas intumescências da medula espinhal possuam pior prognóstico.

O tempo mediano e médio de vida dos animais com complicações do presente estudo foram estimados, respectivamente, em 2 e 7 meses, sendo que as principais causas de morte ou eutanásia estavam relacionadas ao TVM, TCE ou doença inflamatória/ infecciosa. Este resultado está de acordo com estudos realizados por Bentubo et al. (2007) e Fighera et al. (2008), que ao avaliarem as causas de morte e razão para a eutanásia em cães nos estados de São Paulo e Rio Grande do Sul, constataram que as doenças infecciosas e lesões traumáticas estavam entre as principais causas. Além disso, constatou-se no presente estudo que o tempo de vida estimado foi menor para animais mais velhos e mais 
pesados, em comparação com animais mais novos e mais leves. Sabe-se que o risco de desenvolver complicações é maior em cães de raças de grande porte ou obesos, principalmente devido à maior dificuldade na realização do manejo do decúbito nesses pacientes. Olby et al. (2003) constataram que cães mais jovens necessitam de menos tempo para recuperar a capacidade de locomoção, entretanto não foi encontrado nenhum trabalho relatando menor ou maior ocorrência de complicações em animais dessa faixa etária.

Cães e gatos com problemas neurológicos requerem alto grau de atenção do veterinário e de seus tutores, pois as lesões em uma parte do organismo refletem em vários sistemas orgânicos. Muitos dos trabalhos consultados avaliam alterações pontuais e não citam outras complicações além de ocorrência de mielomalácia hemorrágica, infecção urinária, morte e eutanásia, e muitos pacientes com esses problemas são inclusive eliminados do estudo ou da estatística, não refletindo a realidade e a dificuldade que é o manejo desses pacientes. Ainda, muitos estudos que avaliaram a qualidade de vida dos pacientes, o efeito da fisioterapia ou o tempo dedicado pelos proprietários são tendenciosos, pois os tutores que escolheram cuidar dos animais e responderam aos questionários são mais dedicados do que os que não puderam fazer o mesmo (Kathmann et al. 2006, Freeman et al. 2013).

Na medicina humana os fatores que aumentam o risco de desenvolvimento de lesões secundárias, a importância de sua prevenção bem como o manejo adequado e os efeitos da reabilitação já são bem descritos na literatura (McKinley et al. 2001, Cardenas et al. 2004). Já na medicina veterinária, estas informações ainda não estão bem elucidadas, mostrando que há necessidade de realização de mais estudos direcionados a este assunto.

No geral, embora o índice de sobrevivência dos animais com complicações do presente estudo tenha sido alto, grande parte desses animais permaneceram com disfunções neurológicas e incapacidade funcional, o que indica que apenas a sobrevivência não significa um bom resultado ou recuperação em pacientes neurológicos, devendo ser considerada também a presença ou não de sequelas, pois estas condições interferem na qualidade e vida dos animais e de seus tutores.

\section{CONCLUSÕES}

Com base nos resultados pode-se concluir que a incidência de complicações nos gatos e cães com doenças neurológicas do presente estudo foi alta, e que as mais frequentes foram atrofia muscular, distúrbios da micção e defecação e feridas de decúbito.

O principal local de lesão associado ao aparecimento das complicações foi a medula espinhal e a principal etiologia foi o trauma vertebromedular.

O peso e idade dos cães e dos gatos influenciaram negativamente no tempo de sobrevivência dos pacientes. Entretanto, a sobrevivência não significou capacidade funcional normal, visto que vários animais permaneceram com sequelas.

Cães e gatos com doenças neurológicas necessitam de atenção especial, sendo fundamental a orientação do tutor a respeito da real expectativa de recuperação e das dificuldades de manejo que poderão ser encontradas no curso da doença.

Agradecimentos.- À Professora Dra. Jaqueline A. Raminelli, do departamento de Estatística (CCE/UEL), pelo auxílio e orientação na análise estatística.

\section{REFERÊNCIAS}

Amsellem P.M., Toombs J.P., Laverty P.H. \& Breur G.J. 2003. Loss of deep pain sensation following thoracolumbar intervertebral disk herniation in dogs: treatment and prognosis. Compend. Cont. Educ. Pract. 25(4):266-274.

Araújo B.M., Silva A.C., Figueiredo M.L., Fernandes T.H.T., Baraúna Junior D., Bonelli M.A., Diogo C.C., Amorim M.M.A. \& Tudury E.A. 2015. Observações clínicocirúrgicas em fraturas e luxações vertebrais toracolombares em cães. Arq. Bras. Med. Vet. Zootec. 67(4):961-968. http://dx.doi. org/10.1590/1678-4162-7541.

Arias M.V.B., Severo M.S. \& Tudury E.A. 2007. Trauma medular em cães e gatos: revisão da fisiopatologia e do tratamento médico. Semina, Ciênc. Agrárias 28(1):115-134.

Armitage-Chan E.A., Wetmore L.A. \& Chan D.L. 2007. Anesthetic management of the head trauma patient. J. Vet. Emerg. Crit. Care 17(1):5-14. http:// dx.doi.org/10.1111/j.1476-4431.2006.00194.x.

Barcellos H., Rodrigues L., Valle S., Santos L., Brun M., Tomazi G., Ataíde M., et al. 2007. Identificação de agentes e resposta aos tratamentos na cistite neurogênica em cães com lesão na coluna tóraco-lombar. Revta Medvep, Revta Cient. Med. Vet. Peq. Anim. Estimação 4(13):22-30.

Beal M.W., Paglia D.T., Griffin G.M., Hughes D. \& King L.G. 2001. Ventilatory failure, ventilator management, and outcome in dogs with cervical spinal disorders: 14 cases (1991-1999). J. Am. Vet. Med. Assoc. 218(10):15981602. http://dx.doi.org/10.2460/javma.2001.218.1598. PMid:11393372.

Behr S. \& Green R. 2012. Postoperative supportive care and physical rehabilitation, p.591-608. In: Platt S. \& Garosi L. (Eds), Small Animal Neurological Emergencies. Manson Publishing, London. http://dx.doi. org/10.1201/b15214-37.

Bentubo H.D.L., Tomaz M.A., Bondan E.F. \& Lallo M.A. 2007. Expectativa de vida e causas de morte em cães na área metropolitana de São Paulo, Brasil. Ciência Rural 37(4):1021-1026. http://dx.doi.org/10.1590/S010384782007000400016

Bonvicini K.A. \& Cornell K.K. 2007. Are clients truly informed? Communication tools and risk reduction. Compend. Cont. Educ. Pract. Equine 2(2):74-80.

Braund K.G. 1994. Clinical Syndromes in Veterinary Neurology. 2nd ed. Mosby, St Louis. 477p.

Brisson B.A. 2010. Intervertebral disc disease in dogs. Vet. Clin. N. Am., Small Anim. Pract. 40(5):829-858. http://dx.doi.org/10.1016/j.cvsm.2010.06.001. PMid:20732594.

Bubenik L. \& Hosgood G. 2008. Urinary tract infection in dogs with thoracolumbar intervertebral disc herniation and urinary bladder dysfunction managed by manual expression, indwelling catheterization or intermittent catheterization. Vet. Surg. 37(8):791-800. http://dx.doi. org/10.1111/j.1532-950X.2008.00452.x. PMid:19121176.

Cardenas D.D., Hoffman J.M., Kirshblum S. \& McKinley W. 2004. Etiology and incidence of rehospitalization after traumatic spinal cord injury: a multicenter analysis. Arch. Phys. Med. Rehabil. 85(11):1757-1763. http:// dx.doi.org/10.1016/j.apmr.2004.03.016. PMid:15520970.

Coates J.R., Axlund T.W., Dewey C.W. \& Smith J. 2006. Hydrocephalus in dogs and cats. Compend. Cont. Educ. Pract. 28(2):136.

Coates J.R. \& Wininger F.A. 2010. Canine degenerative myelopathy. Vet. Clin. N. Am., Small Anim. Pract. 40(5):929-950. http://dx.doi.org/10.1016/j. cvsm.2010.05.001. PMid:20732599.

Colosimo E.A. \& Giolo S.R. 2006. Análise de Sobrevivência Aplicada. Edgard Blücher, São Paulo. 392p.

Davis G.J. \& Brown D.C. 2002. Prognostic indicators for time to ambulation after surgical decompression in nonambulatory dogs with acute thoracolumbar disk extrusions: 112 cases. Vet. Surg. 31(6):513-518. http://dx.doi. org/10.1053/jvet.2002.36015. PMid:12415519.

De Decker S., Wawrzenski L.A. \& Volk H.A. 2014. Clinical signs and outcome of dogs treated medically for degenerative lumbosacral stenosis: 98 cases 
(2004-2012). J. Am. Vet. Med. Assoc. 245(4):408-413. http://dx.doi. org/10.2460/javma.245.4.408. PMid:25075824.

De Lahunta A. \& Glass E. 2015a. Veterinary Neuroanatomy and Clinical Neurology. 4th ed. Saunders Elsevier, St Louis. 600p.

De Lahunta A. \& Glass E. 2015b. Lower motor neuron: spinal nerve, general somatic efferent system, p.102-160. In: Ibid. (Eds), Veterinary Neuroanatomy and Clinical Neurology. 4th ed. Saunders Elsevier, St Louis.

De Risio L., Sharp N.J., Olby N.J., Muñana K.R. \& Thomas W.B. 2001. Predictors of outcome after dorsal decompressive laminectomy for degenerative lumbosacral stenosis in dogs: 69 cases (1987-1997). J. Am. Vet. Med. Assoc. 219(5):624-628. http://dx.doi.org/10.2460/javma.2001.219.624. PMid:11549090.

Dewey C.W. 2000. Emergency management of the head trauma patient: principles and practice. Vet. Clin. N. Am., Small Anim. Pract. 30(1):207-225, vii-viii. http://dx.doi.org/10.1016/S0195-5616(00)50010-2. PMid:10680216.

Dewey C.W. \& Da Costa R. 2016. Practical Guide to Canine and Feline Neurology. 3rd ed. Wiley Blackwell, Iowa. 688p.

Fighera R.A., Souza T.M., Silva M.C., Brum J.S., Graça D.L., Kommers G.D., Irigoyen L.F. \& Barros C.S.L. 2008. Causas de morte e razões para eutanásia de cães da Mesorregião do Centro Ocidental Rio-Grandense. Pesq. Vet. Bras. 28(4):223-230. http://dx.doi.org/10.1590/S0100-736X2008000400005.

Forterre F., Tomek A., Rytz U., Brunnberg L., Jaggy A. \& Spreng D. 2007. Iatrogenic sciatic nerve injury in eighteen dogs and nine cats (1997-2006). Vet. Surg. 36(5):464-471. http://dx.doi.org/10.1111/j.1532-950X.2007.00293.x. PMid:17614928.

Freeman P.M., Holmes M.A., Jeffery N.D. \& Granger N. 2013. Time requirement and effect on owners of home-based management of dogs with severe chronic spinal cord injury. J. Vet. Behav. Clin. Appl. Res. 8(6):439-443. http://dx.doi.org/10.1016/j.jveb.2013.06.001.

Garosi L. \& Adamantos S. 2011. Head trauma in the cat. 2. Assessment and management of traumatic brain injury. J. Feline Med. Surg. 13(11):815-823. http://dx.doi.org/10.1016/j.jfms.2011.09.003. PMid:22063206.

Grasmueck S. \& Steffen F. 2004. Survival rates and outcomes in cats with thoracic and lumbar spinal cord injuries due to external trauma. J. Small Anim. Pract. 45(6):284-288. http://dx.doi.org/10.1111/j.1748-5827.2004. tb00236.x. PMid:15206472.

Hillman R.B., Kengeri S.S. \& Waters D.J. 2009. Reevaluation of predictive factors for complete recovery in dogs with nonambulatory tetraparesis secondary to cervical disk herniation. J. Am. Anim. Hosp. Assoc. 45(4):155163. http://dx.doi.org/10.5326/0450155. PMid:19570897.

Indrieri R.J. 1988. Lumbosacral stenosis and injury of the cauda equina. Vet. Clin. N. Am., Small Anim. Pract. 18(3):697-710. http://dx.doi.org/10.1016/ S0195-5616(88)50062-1. PMid:3289251.

Jeffery N.D. 2010. Vertebral fracture and luxation in small animals. Vet. Clin. N. Am., Small Anim. Pract. 40(5):809-828. http://dx.doi.org/10.1016/j. cvsm.2010.05.004. PMid:20732593.

Jeffery N.D., Levine J.M., Olby N.J. \& Stein V.M. 2013. Intervertebral disk degeneration in dogs: consequences, diagnosis, treatment, and future directions. J. Vet. Intern. Med. 27(6):1318-1333. http://dx.doi.org/10.1111/ jvim.12183. PMid:24010573.

Jeffery N.D., Barker A.K., Hu H.Z., Alcott C.J., Kraus K.H., Scanlin E.M., Granger N. \& Levine J.M. 2016. Factors associated with recovery from paraplegia in dogs with loss of pain perception in the pelvic limbs following intervertebral disk herniation. J. Am. Vet. Med. Assoc. 248(4):386-394. http://dx.doi. org/10.2460/javma.248.4.386. PMid:26829270.

Jerram R.M., Hart R.C. \& Schulz K.S. 1997. Postoperative management of the canine spinal surgery patient. Comp. Cont. Educ. Pract. Vet. 19(2):147-160.

Kathmann I., Cizinauskas S., Doherr M.G., Steffen F. \& Jaggy A. 2006. Daily controlled physiotherapy increases survival time in dogs with suspected degenerative myelopathy. J. Vet. Intern. Med. 20(4):927-932. http://dx.doi. org/10.1111/j.1939-1676.2006.tb01807.x. PMid:16955818.

Laitinen O.M. \& Puerto D.A. 2005. Surgical decompression in dogs with thoracolumbar intervertebral disc disease and loss of deep pain perception: a retrospective study of 46 cases. Acta Vet. Scand. 46(1/2):79-85. http:// dx.doi.org/10.1186/1751-0147-46-79. PMid:16108215.

LeCouteur R.A. 2011. Canine idiopathic inflamatory CNS disease. NAVC Clinician's Brief, Tulsa, p.19-23.

Levine J.M., Levine G.J., Johnson S.I., Kerwin S.C., Hettlich B.F. \& Fosgate G.T. 2007. Evaluation of the success of medical management for presumptive thoracolumbar intervertebral disk herniation in dogs. Vet. Surg. 36(5):482491. http://dx.doi.org/10.1111/j.1532-950X.2007.00295.x. PMid:17614930.

Levine J.M., Budke C.M., Levine G.J., Kerwin S.C., Hettlich B.F. \& Slater M.R. 2008. Owner-perceived, weighted quality-of-life assessments in dogs with spinal cord injuries. J. Am. Vet. Med. Assoc. 233(6):931-935. http://dx.doi. org/10.2460/javma.233.6.931. PMid:18795855.

Lexmaulová L., Novotná R., Raušer P. \& Nečas A. 2008. Complications related to surgical treatment of intervertebral disc disease in dogs. Acta Vet. Brno 77(2):269-276. http://dx.doi.org/10.2754/avb200877020269.

Lorenz M.D. \& Kornegay J.N. 2006. Neurologia Veterinária. 4ª ed. Manole, Barueri, SP. 467p.

Lorenz M.D., Coates J.R. \& Kent M. 2011. Paresis of one limb, p.94-108. In: Ibid. (Eds), Handbook of Veterinary Neurology. 5th ed. Saunders Elsevier, St Louis. http://dx.doi.org/10.1016/B978-1-4377-0651-2.10005-0.

McKinley W.O., Seel R.T., Gadi R.K. \& Tewksbury M.A. 2001. Nontraumatic vs. traumatic spinal cord injury: a rehabilitation outcome comparison. Am. J. Phys. Med. Rehabil. 80(9):693-699, quiz 700, 716. http://dx.doi. org/10.1097/00002060-200109000-00010. PMid:11523972.

Meij B.P. \& Bergknut N. 2010. Degenerative lumbosacral stenosis in dogs. Vet. Clin. N. Am., Small Anim. Pract. 40(5):983-1009. http://dx.doi. org/10.1016/j.cvsm.2010.05.006. PMid:20732601.

Mendes D.S. \& Arias M.V.B. 2012. Traumatismo da medula espinhal em cães e gatos: estudo prospectivo de 57 casos. Pesq. Vet. Bras. 32(12):1304-1312. http://dx.doi.org/10.1590/S0100-736X2012001200015.

Millichamp N.J., Dziezyc J. \& Kern T.J. 1990. Ulcerative keratitis. Vet. Clin. N. Am., Small Anim. Pract. 20(3):643-666. http://dx.doi.org/10.1016/ S0195-5616(90)50055-8.

Nakamoto Y., Ozawa T., Katakabe K., Nishiya K., Mashita T., Morita Y., Yasuda N., Ishii Y., Nakaichi M. \& Itamoto K. 2008. Usefulness of an early diagnosis for the favorable prognosis of fibrocartilaginous embolism diagnosed by magnetic resonance imaging in 10 small- to middle-sized dogs. Vet. Res. Commun. 32(8):609-617. http://dx.doi.org/10.1007/s11259-008-9061-y. PMid:18491211.

Nakamoto Y., Ozawa T., Katakabe K., Nishiya K., Yasuda N., Mashita T., Morita Y. \& Nakaichi M. 2009. Fibrocartilaginous embolism of the spinal cord diagnosed by characteristic clinical findings and magnetic resonance imaging in 26 dogs. J. Vet. Med. Sci. 71(2):171-176. http://dx.doi.org/10.1292/ jvms.71.171. PMid:19262027.

Nicoll S.A. \& Remedios A.M. 1995. Recumbency in small animals: pathophysiology and management. Small Anim. Surg. 17(11):1367-174

Olby N. 2010. The pathogenesis and treatment of acute spinal cord injuries in dogs. Vet. Clin. N. Am., Small Anim. Pract. 40(5):791-807. http://dx.doi. org/10.1016/j.cvsm.2010.05.007. PMid:20732592.

Olby N., Levine J., Harris T., Muñana K., Skeen T. \& Sharp N. 2003. Long-term functional outcome of dogs with severe injuries of the thoracolumbar spinal cord: 87 cases (1996-2001). J. Am. Vet. Med. Assoc. 222(6):762769. http://dx.doi.org/10.2460/javma.2003.222.762. PMid:12675299.

Olby N.J., MacKillop E., Cerda-Gonzalez S., Moore S., Muñana K.R., Grafinger M., Osborne J.A. \& Vaden S.L. 2010. Prevalence of urinary tract infection in dogs after surgery for thoracolumbar intervertebral disc extrusion. J. 
Vet. Intern. Med. 24(5):1106-1111. http://dx.doi.org/10.1111/j.19391676.2010.0567.x. PMid:20695988.

Posner L.P., Mariani C.L., Swanson C., Asakawa M., Campbell N. \& King A.S. 2014. Perianesthetic morbidity and mortality in dogs undergoing cervical and thoracolumbar spinal surgery. Vet. Anaesth. Analg. 41(2):137-144. http://dx.doi.org/10.1111/vaa.12127. PMid:24588930.

Rossmeisl Junior J.H., White C., Pancotto T.E., Bays A. \& Henao-Guerrero P.N. 2013. Acute adverse events associated with ventral slot decompression in 546 dogs with cervical intervertebral disc disease. Vet. Surg. 42(7):795806. PMid:23980621.

Ruddle T.L., Allen D.A., Schertel E.R., Barnhart M.D., Wilson E.R., Lineberger J.A., Klocke N.W. \& Lehenbauer T.W. 2006. Outcome and prognostic factors in nonambulatory Hansen Type I intervertebral disc extrusions: 308 cases. Vet. Comp. Orthop. Traumatol. 19(1):29-34. http://dx.doi. org/10.1055/s-0038-1632970. PMid:16594541.

Sande A. \& West C. 2010. Traumatic brain injury: a review of pathophysiology and management. J. Vet. Emerg. Crit. Care 20(2):177-190. http://dx.doi. org/10.1111/j.1476-4431.2010.00527.x. PMid:20487246.

Sharma D. \& Holowaychuk M.K. 2015. Retrospective evaluation of prognostic indicators in dogs with head trauma: 72 cases (January-March 2011). J. Vet. Emerg. Crit. Care 25(5):631-639. http://dx.doi.org/10.1111/vec.12328. PMid:26112259.
Sharp N.J.H. \& Wheeler S.J. 2005a. Postoperative care, p.339-362. In: Ibid. (Eds), Small Animal Spinal Disorders: diagnosis and surgery. 2nd ed. Elsevier Mosby, Philadelphia. http://dx.doi.org/10.1016/B978-0-72343209-8.50019-4.

Sharp N.J.H. \& Wheeler S.J. 2005b. Small Animal Spinal Disorders: diagnosis and surgery. 2nd ed. Elsevier Mosby, Philadelphia. 722p.

Sims C., Waldron R. \& Marcellin-Little D.J. 2015. Rehabilitation and physical therapy for the neurologic veterinary patient. Vet. Clin. N. Am., Small Anim. Pract. 45(1):123-143. http://dx.doi.org/10.1016/j.cvsm.2014.09.007. PMid:25440754.

Slatter D. 2003. Textbook of Small Animal Surgery. 3rd ed. Elsevier Science, USA. 2713p.

Stiffler K.S., Stevenson M.A.M., Sanchez S., Barsanti J.A., Hofmeister E. \& Budsberg S.C. 2006. Prevalence and characterization of urinary tract infections in dogs with surgically treated type 1 thoracolumbar intervertebral disc extrusion. Vet. Surg. 35(4):330-336. http://dx.doi.org/10.1111/j.1532950X.2006.00153.x. PMid:16756612.

Thomas W.B. 2010. Hydrocephalus in dogs and cats. Vet. Clin. N. Am., Small Anim. Pract. 40(1):143-159. http://dx.doi.org/10.1016/j.cvsm.2009.09.008. PMid:19942061.

Vianna C.G. \& Arias M.V.B. 2013. Estudo prospectivo de traumatismo cranioencefálico em 32 cães. Revta Bras. Med. Vet. 35(1):93-99. 